\title{
Ethics, organ donation and tax: a proposal
}

\author{
Thomas Søbirk Petersen, ${ }^{1}$ Kasper Lippert-Rasmussen ${ }^{2}$
}

\begin{abstract}
${ }^{1}$ Department of Philosophy, University of Roskilde, Roskilde, Denmark

${ }^{2}$ Department of Political Science, Aarhus University, Aarhus, Denmark
\end{abstract}

\section{Correspondence to} Dr Thomas Søbirk Petersen, Department of Philosophy, University of Roskilde, Roskilde 4000, Denmark; thomassp@ruc.dk

Received 15 August 2011 Revised 26 October 2011 Accepted 18 November 2011

\begin{abstract}
Five arguments are presented in favour of the proposal that people who opt in as organ donors should receive a tax break. These arguments appeal to welfare, autonomy, fairness, distributive justice and selfownership, respectively. Eight worries about the proposal are considered in this paper. These objections focus upon no-effect and counter-productiveness, the Titmuss concern about social meaning, exploitation of the poor, commodification, inequality and unequal status, the notion that there are better alternatives, unacceptable expense, and concerns about the veto of relatives. The paper argues that none of the objections to the proposal is very telling.
\end{abstract}

The shortage of organs for transplant has a serious, negative impact on a very large number of people worldwide. In the USA alone at least 6000 patients die each year while on waiting lists for new organs-a rough equivalent of twice the number of people killed in the 9/11 terror attacks in 2001. ${ }^{12}$ The figures are comparable in many western countries. In the UK, for instance, the number of deaths due to organ shortage is approximately 1000 each year. ${ }^{3}$ What is even more serious is that the number of people dying before they are assigned a place on a waiting list is even greater than the number of people dying while on the list. Therefore, in the USA more than 100000 possible transplant candidates die each year before being placed on a waiting list. ${ }^{4}$ We must add to this the following facts: (1) Most of the waiting lists are very long; studies show that the number of people on the waiting list for an organ transplant in the USA is approximately $112000 .^{5}$ (2) The time spent on the waiting list (or before one is assigned) is often terrifying and full of worry both for the potential donee and his or her friends and family, and the time people are on the waiting list is increasing. ${ }^{6}$ (3) There is strong evidence that the gap between supply and demand will increase, because more people are living longer and getting diabetes, and are thus becoming prone to organ failure. $^{7}$ This is an avoidable tragedy. We should figure out a way of preventing it.

The shortage of organs is especially severe in countries such as the USA, the UK and Denmark, where donors are required to opt in, generally on the basis of 'informed consent'. In such countries people can sign up to disclose their willingness to donate their organs. On average approximately 15\% of people have stated whether or not they are willing to donate, and only half of these have declared that they are indeed willing to donate. ${ }^{8}$
Elsewhere in the developed world-for example, in Austria, Belgium, France, Hungary, Poland and Portugal-an opt-out system of 'presumed consent' operates, according to which people are automatically treated as donors but can opt out whenever they want. Here the number of 'registered' donors is much higher, at approximately $98-99.8 \% .^{9}$ The obvious conclusion is that the contrasting percentages here reflect differing 'capture rates'when it comes to registered donors-under the opt-in and opt-out systems.

Few would dispute that arrangements involving presumed consent require justification in a way that their counterparts with informed, actual consent do not. And presumably nobody in their right mind would deny that capture rates are important. The question we therefore wish to address is whether it is possible to devise an opt-in system that is better suited than the one currently operating in the USA, the UK and Denmark to increase human organ supply. One idea has already been tried. In 2010, Israel implemented a broadly reciprocal opting-in system, in which, if you sign up and demonstrate your willingness to donate, you receive priority if it subsequently turns out that you need an organ. Like the Israeli government, we anticipate that this system will make more organs available, simply as a result of motivating more people to become donors. ${ }^{10}$ However, because the initiative is very young, we have been unable to obtain data verifying this conjecture. ${ }^{11}$ One can imagine a more stringently reciprocal-supply as well as demand-side-opting-in system in which one signs up not only to donate one's organs, but also to receive another's should the need arise, possibly on the very same form. Such a system is more stringent because, presumably, most people would feel some inhibition in ticking the box indicating 'I'd like to receive someone else's organs should I need to' while not ticking the box for 'I will donate my own organs should someone else need them' and if they do so despite this inhibition, they will get the lower priority they presently get under the Israeli system. A stringently reciprocal opting-in system of this sort, like the somewhat less stringent arrangements operating in Israel, would, we believe, be likely to make more organs available for transplantation than conventional systems with a simple opting-in structure.

For various reasons-some, in the first instance, at any rate, political-opting-out systems, the Israeli variant of opting-in and demand-side optingin systems are not always feasible. In what follows we will largely set aside both conventional optingout and reciprocal opting-in systems and focus on 
a proposal that might yet ensure that more people in opt-in countries currently showing little appetite for arrangements relying on presumed consent will opt in. In principle our proposal can be accommodated within either an opting-out or an opting-in model. Plainly, though, its main value lies with the latter, and that is what we will be concentrating upon. In the case of the former model, it might well be thought unnecessary to raise capture rates above $98-99.8 \%$.

\section{A PROPOSAL: TAX BREAKS}

Many suggestions as to how organ supply could be improved through financial incentives have been made, and a good number of these have been discussed at length in the medical ethics literature. Different kinds of markets in human body parts are critically discussed in Taylor ${ }^{12}$ and Blumstein et al ${ }^{13}$ for example, and the ethical concerns raised by reimbursement for the funeral services of deceased donors are discussed in Delmonico et al. ${ }^{2}$ In what follows, we would like to elaborate, and critically discuss, a relatively overlooked idea: namely, that a tax benefit should be used to incentivise donation. In principle, there are two general approaches here: one is to impose extra tax on people who decide not to opt in, the other is to offer a tax break of some sort to people who agree to opt in. Albeit economically equivalent, these approaches are likely to be perceived rather differently. For example, the former, unlike the latter, might be thought to involve the assertion of some kind of public ownership over citizens' bodily parts, but in economic terms they are equivalent. ${ }^{14}$ It seems likely that, politically, the second approach would be more workable. Accordingly, this is the one we will explore.

Depending on the generosity of the scheme, a tax benefit scheme would work in one or both of two ways. Its primary effect would be to compensate people for the negative impacts associated with making a donation. Quite what those impacts are would need to be investigated empirically, but judging by the number of people who think they should donate but do not do so, it seems undeniable that, in some sense, costs do attach to organ donation. Secondarily, the scheme would deliver a positive incentive to donors, or their relatives, to go through with donations and in that way it would increase the number of organs available for transplantation. Briefly, the difference between these two effects is this: compensation means that people are not made worse off by making their organs available; incentives mean they are made better off.

At least three tax benefit schemes are available here. One is that a person receives an annual tax credit (say, £200) in exchange for consenting to be an organ donor on his or her death. ${ }^{15}$ In a variant of this arrangement the donor could receive a much larger, one-off tax credit the year he or she signs the form consenting to donation. In both of these cases donors may be able to opt out should they change their mind, provided they pay back the taxes saved. A second tax-based incentive would be that your relative (or some other recipient such as a nominated charity) receives a tax credit on condition that you are signed up as a donor and that your organs actually are transplanted after your death. A third possibility would be for you to receive a tax credit when, as a living donor, you donate an organ, such as your kidney, or a lung or part of your liver, that you can manage without. ${ }^{516}$ A form of this third option has been adopted in the USA state of Wisconsin, which in 2004 passed a law that allows donors to deduct from their taxable income any costs they incur as the result of donating part of a liver or a kidney. A maximum deduction of US\$10000 is allowed, and a one-off payment is made. When a live donor makes a kidney available for transplantation the sum needed for compensation will obviously be quite significant, probably well above US\$10000. The first two schemes could be combined; they could also be extended to live donors, as they are in effect in Wisconsin. However, the following discussion will focus on the ethics of the first scheme-ie, the scheme in which a person receives a tax credit when he or she agrees to become an organ donor on his or her death. The reasonable question of whether our proposals would be illegal is beyond the scope of this paper. We merely note in passing that there is a clear sense in which illegality is not in itself a powerful objection; it may be that the law needs updating.

\section{THE ARGUMENTS FOR TAX CREDITS}

Provided the alternative is an opt-in scheme with no reward or compensation for donation, several arguments support the suggestion that people who donate their organs should receive a tax credit. These arguments appeal to a wide range of ethical principles, some of which may be in conflict with one another. For the present purposes, though, any potential argumentative disharmony is not a problem. Our aim is to show that strong reasons favour our proposal whichever of a broad range of ethical principles you subscribe to. We are not endorsing the arguments sketched in this section collectively.

The most obvious argument is welfare based: it is that a tax credit scheme would increase the size of the pool of organs available for transplantation. Although economic incentives do not always work as intended, studies show that they often work. ${ }^{13}$ Studies have demonstrated, for instance, that people actually donate more to charity the more of the donations they are able to deduct from their taxes. ${ }^{17}$ If incentives work in the same way in the case of organ transplantation, a lot of lives would probably be saved. In any case, the best way to find out how incentives affect the number of donors is by actually implementing the scheme and seeing what happens. If there are no, or only weak, objections to the scheme, a small probability of increasing the number of available organs may suffice to justify the introduction of the scheme as a temporary measure whose continuation depends on a subsequent positive evaluation. We take it for granted that nearly all participants in the debate-consequentialists and most deontologists-will regard the fact that it will save lives as a strong reason to adopt our proposal, even if they are doubtful about the mechanism itself. Furthermore, if everything else is equal, increasing the number of organs available for transplantation could shorten (or eliminate) waiting lists, shorten waiting times, and thereby improve wellbeing for many people. If one sees 'transplant tourism' (or organ theft) as a morally bad thing, an increase in the number of organs for transplantation in rich countries, brought about by a tax credit for willingness to donate, will minimise, or eliminate altogether, such tourism (or theft).

Second, a tax credit might nudge people to do what they really want to do. Several studies conducted in various countries indicate that approximately $80 \%$ of the population wants to donate organs, ${ }^{18} 19$ but in countries with an opting-in system many people fail to do what, apparently, they really want to do. The reasons for this include complacency, lack of knowledge about the options or the procedure, and the simple fact that most of us find it unpleasant to be confronted with our own death. A tax credit could be the ideal nudge that changes behaviour in a direction that most people welcome; it might help us to act in the way we think, reflectively, we should. So in this sense a tax credit would actually support most people's 
autonomy. Admittedly, such studies may to some extent misrepresent people's attitudes. After all, when faced with a moral question some people feel the need to give a so-called 'correct moral' answer that may not correspond with what they truly want to do. Yet, such surveys are not without value. First, presumably not all anonymous respondents who would not donate their organs are reluctant to give true but 'morally incorrect' answers. Second, given that up to $80 \%$ respond that they want to donate organs, the misrepresentation would have to be massive for the conclusion that a majority of the population wants to become organ donors when dead to be false.

Third, considerations of fairness appear to support a tax credit scheme in two ways at least. Compensating people who do something good-for example, creating tax incentives to encourage people to donate money to charity-is a well-known practice and is considered by many people to be both legally and morally desirable because it increases the total amount of money donated. ${ }^{17}$ Why not use tax credits to save the lives of people who need an organ then? People who endorse tax benefits for donations to charity should at least explain why people who are willing to donate their organs after death should not receive a tax credit when those who donate money to charity receive beneficial treatment from the taxman. After all, the former, unlike the latter, seems to involve psychological costs. Furthermore, on top of the unfairness in the differential treatment of organ donors relative to other donors it also seems unfair that everybody other than the donor receives something when organs are transplanted. ${ }^{12} 13$ The medical staff and the medical firms all receive financial compensation for their work, and for the medicine required to make the organ transplant a success; they are not expected to offer their services for free. The recipient of the organ, or donee, will have his or her life prolonged, and relatives will benefit by not losing a loved one.

Fourth, considerations of distributive justice will favour a tax credit scheme, when the extra organs made available are used mostly to help disadvantaged patients. We offer two illustrations. To begin with, assume justice has a 'sufficientarian' component; in other words, that people have a right to a minimally flourishing life. ${ }^{20}$ While this notion may be somewhat vague, it is clear that, if it has any bite all, a young person in immediate, unmet need of a new organ does not yet have his or her right to a minimally flourishing life satisfied. If, alternatively, we think of justice in terms of equal opportunities for welfare, it would seem similarly reasonable to suppose that making organs available to people who need them-many of whom will be young, and will have lived for many years with a reduced quality of life as a result, say, of their kidney problems-will reduce inequality of opportunity for welfare. ${ }^{20}$

Finally, of course some people reject the idea of distributive justice, in part because they think it involves asserting that some people own others, in their persons and their labour, and that this conflicts with the idea that people own themselves, ie, the self-ownership thesis. ${ }^{21} 22$ However, even self-ownership is compatible with our proposal. According to the self-ownership thesis people own their own bodies and are free to dispose of them in whatever way they see fit (provided they do not use them in ways violating the rights of others). Confiscating people's organs, certainly, would violate their self-ownership rights. (The need to obtain the patient's consent in the context of surgical interventions is often explained in terms of the patient's self-ownership of his or her body.) However, offering them a sum of money to consent to the use of their organs after their death does not. Indeed, preventing them from so consenting would violate their self-ownership.
This concludes our presentation of five arguments for the view that voluntary organ donation should be recognised in tax credits. We believe it is pretty indisputable: (1) that there is a strong case in favour of a tax credit scheme of the sort we have described; (2) that this case is robust across a wide range of ethical principles; and (3) that the real issue is thus whether there are any powerful objections to such a scheme. In what follows we therefore present and evaluate eight objections. Broadly speaking, two types of objection can be made: one alleges that the tax credit mechanism goes too far, the other that it does not go far enough (eg, because the organs of the deceased should be considered a common resource capable of being confiscated by the state without consent or compensation). ${ }^{23}$ We will ignore the latter. The objections of the first type that we consider do not exhaust the possibilities, but we think these are the ones that will be (and most often are) employed against tax incentives or other kinds of economic inducement to donate organs.

\section{EIGHT WORRIES}

\section{The no-effect and counterproductiveness objection}

One worry about the proposal is that, despite expectations, it might fail to induce more people to opt in to donation schemes. This is the no-effect objection. Ultimately, the question of how effectively tax credits affect the number of organs available for transplantation is empirical. Only implementation and review can reveal if more people will sign up as organ donors with the scheme in place.

We make three observations about the no-effect objection. First, at least some studies suggest that the offer of a fairly modest cash payment would increase the number of people willing to donate. ${ }^{24}$ Second, the no-effect objection gives us no reason not to trial a tax credit scheme and assesses its effects. True, it might show that the welfare argument for the scheme does not apply, but it does not offer any reasons against the scheme. Third, the arguments from fairness and self-ownership stand even if tax credits fail to raise the number of donors.

A more serious concern about the tax scheme is that it may actually reduce the number of people who are willing to donate organs. This is the counterproductiveness objection. It would present a serious challenge to the tax credit scheme if it were correct. Part of our response above, however, namely that the arguments from fairness and self-ownership stand, also applies to the counterproductiveness objection. Moreover, as a tax credit scheme would appear, in commonsense terms, to make organ donation more, not less, attractive, a strong argument would be needed to support the counterproductiveness objection. In general, tax incentives strengthen the pattern of behaviour they render more financially attractive. Why should organ donation be any different in this respect? Finally, few who oppose our scheme are likely to press this particular objection. In point of fact, some of the objections we discuss below, such as the exploitation objection, presuppose that financial incentives increase public willingness to donate organs.

\section{Titmuss' objection}

It might be suggested that the counterproductiveness objection gains support from Richard M. Titmuss' parallel objection to payments for blood donations. His objection is empirically based. It is alleged that paying for blood changes the social meaning of giving blood, and that this may result in reduced donations. The change in the social meaning, according to Titmuss, comes about because financial incentives to donate 
organs deny individuals the chance of entering into a gift relationship with those who need organs. This is problematical, according to Titmuss, because: 'The social relations set up by gift exchanges are among the most powerful forces which bind a social group together.' Therefore, governments should: '... weaken market forces which put men in positions where they have little opportunity to make moral choices or to behave altruistically if they wish so'. ${ }^{25}$ In keeping with this reasoning, a tax credit for organ donation could (1) ensure that such donation is no longer seen as a pure gift. In doing so it would give potential donors less opportunity to make a moral choice, ie, deprive them of a valuable option. This (2) would undermine social cohesion and (3) could erode public willingness to donate.

If all this is true, our proposal certainly appears to be problematical. However, it is less clear which, if any, of the arguments we offered in the previous section the Titmuss objection defeats. Of course, to be an objection, it need not defeat any of these arguments. It may simply point to objectionable features of our scheme that are independent of the reasons so far adduced in its favour.

Howsoever that may be, we are sceptical about claims (1) and (2). First of all, we should note that we give gifts, according to Titmuss, because we have a social and biological urge to help people in need. ${ }^{25}$ However, if, collectively, we can help more people in need by offering the donor a tax credit, this seems to be the right thing to do in order to satisfy the urge to help people in need. The important thing must be to save people from dying, and from a moral point of view it is less important whether people are able to make gifts. At a reflective level we should be capable of understanding that this is the right way to satisfy our urge to give.

Second, presumably a society is strengthened Titmuss-style not by the sheer opportunity for citizens to make moral choices, but by the fact that people exercise this opportunity. If so, society might be strengthened under a tax break system, in which, out of mixed or purely financial motives, more people make a better moral choice by being willing to donate than under a system without tax breaks in which, out of purely nonfinancial motives, fewer people choose to donate. This is especially so given that the first option saves lives and the second involves letting people die. In any case, tax credits need not be compulsory; within our scheme, people could retain the option of donating their organs without receiving anything in return, or they could give the equivalent of the monetary value of their tax break to charity. In fact, was one to donate and receive a tax credit, even though one would have donated whether or not a credit was on offer, one would still be acting in an altruistic spirit of the kind Titmuss values. ${ }^{23}$ In all societies sex is offered for money, but that, it seems, does not prevent people from engaging in acts of sex with a very different social meaning from that which standard market transactions make possible. Why, one may ask, cannot the same be true of donations of organs?

Third, although it is not a gift in the ordinary sense of the word-that is to say, it involves compensation for the 'giving' and a mere consent to give (and in most situations you will not end up giving anything, ie, your organs will not be useful for transplantation purposes) - organ donation is clearly something of very great importance to the receiver and his or her relatives and friends. On the other hand, if we accept that donated organs should be gifts, and that they are not gifts once you stand to receive a tax credit for your willingness to donate, it can still be claimed that it is more important to prevent people from dying than it is to ensure that organ donation is a form of gifting. Note also that Titmuss will need to confine his point. Certainly one wonders: why is it that organs must be given without any return, while the services of doctors who carry out the transplantations need not be? The Titmuss objection seems to prove too much. As Cécile Fabre has said, it seems to show that 'taxation should be voluntary'23 (p. 64).

Finally, without stretching matters too much, we believe, tax credits can themselves be interpreted as gifts-from the state to individuals who have done something for the common good. If this is correct, tax credits may serve to increase the number of gift relations in society. That ought to please those looking at the issues in the way Titmuss recommends. Moreover, it is unclear why a tax break will prevent organ donation itself from being seen as a gift, especially if the tax credit is simply thought to compensate the donor for the costs he or she has incurred. Certainly, tax breaks for ordinary donations to charity have not changed their meaning such that they are no longer thought of as gifts.

\section{Exploitation}

Some may object that tax benefits are more attractive to less affluent people than they are to those who are well off, and that this might well lead to the exploitation of people in lower income brackets.

This is not a convincing argument, for several reasons. First, it is not clear what is meant by the term 'exploitation', and that needs to be settled in order to assess the objection. One way, out of many, to define 'exploitation' is to say that X exploits Y, if (1) $X$ makes use of the fact that $Y$ is vulnerable in some respect to make (eg, by coercing) Y act in a certain way, and (2) Y would have been better off had $X$ not acted in this way, ${ }^{26} 27$ but is tax redit-backed organ donation necessarily a case of exploitation on this definition? It seems not. Let us suppose that poor people are more likely to accept a tax credit for their willingness to donate than those who are well off. As long as the poor can benefit from the arrangement, and make an informed and voluntary choice that helps others in need, it is difficult to view our proposal as exploitative. The concern about exploitation of the poor is further guarded against by the fact that the tax credits at issue (of $£ 200$ per annum) would probably not enrich anyone sufficiently to coerce them into making a decision that they would not otherwise make. The credits would merely benefit them financially. Furthermore, and very importantly, if one is worried about exploitation, and if it is true that poor people have more organ failures than rich people, then the poor would benefit even more than the well off from a system of donation-linked tax credits. Finally, and most importantly, because one does not need one's organs after death, it is unclear that poor people are vulnerable in some respect (other than that they need money more than others) that the state takes advantage of when it offers a tax credits for postmortem donations-unless, of course, one thinks that poor people are exploited whenever they are offered money in exchange for something. Premortem donations are a different matter, of course, but these are not recommended in our proposal. It might plausibly be objected that, on the present definition, third-world sweatshops are not exploitative provided the workers' only alternative is unemployment, in which case they would be even worse off. To accommodate this intuition, one could omit (2) from the definition of exploitation. Note, however, that even so revised the definition of exploitation does not rule out the possibility that tax breaks for organ donations might be non-exploitative, for example, if only persons deemed non-vulnerable are eligible for the tax break. However, our proposal might involve exploitation on a different definition of exploitation, for example, one according to which it 
is sufficient for exploitation that (1) above holds and (3) that X (or others) benefit much more from X's action than Y.

In any case, even if the exploitation worry applies and one should be worried by the exploitation of poor people in developing countries when it comes to organ donation, one should nevertheless welcome a financial incentive in affluent countries. For reduced waiting lists in rich countries would, as we have argued, have the knock-on effect that fewer people in poor countries are exposed to the alleged exploitation involved in organ tourism, and that fewer people are exploited by organ theft. Also, insofar as a tax credit scheme involves the exploitation of relatively poor people in wealthy countries, presumably, this exploitation is less worrying than the worse exploitation that occurs when desperately poor people sell their organs on the black market. Obviously, deontologists who think that we should not exploit people through the state even when that will reduce the overall scale of exploitation will not be impressed by this point. At least it shows that a concern for exploitation in relation to organs may take such a non-deontological form, in which it favours our proposal.

\section{Commodification}

Is a tax credit system of organ donation objectionable because it involves the commodification of human body parts and/or paves the way to the commodification of human body parts? There are many ways to interpret this concern. One has to do with the possible harmful effects that such commodification can have on people's attitudes to one another. For instance, some might worry that we would begin to view each other more as objects than persons, each with goals of his or her own. Another worry has to do with the idea that there is something wrong as such with putting a price on one's willingness to donate-that this violates individual dignity or the 'sacred' notion that all persons are in some sense priceless. ${ }^{28} 29$

Tax credits do not entail commodification in the standard sense, which would indicate some kind of sale or market in organs. The monetary value of a tax credit is fixed, unlike the payments made in a market. Again, unlike the situation in a market, tax credits cannot be turned over to (traded with) another person; they are linked to the specific tax profile of each person. Nor can the giver of the organ sell to the highest bidder or for frivolous purposes. Indeed, the donor has no influence on who receives the organ and the donee is not the highest bidder, but the person in, say, the greater need. Many countries offer tax credits, or premiums, to encourage people to have more children, or charge people who adopt children a large fee, but no one seriously thinks that children have been commodified by this; the same goes for tax incentives encouraging donations to charities (especially when these represent compensation for the inconvenience involved for the donor).

Second, even if there were a genuine risk of commodification in a broad sense of that term, so long as the tax credit system increased the supply of organs, the volume of organ tourism would be reduced, and in this way the number of commodifying transactions would decrease. So, once again, if one objects to our proposal on the grounds that it would increase immoral commodification, one should concede that there is a strong reason in its favour-namely, that it would probably limit organ tourism and the black market for organs that exists in some countries.

Third, even if tax credits are a form of commodification, the system of organ donation they play a role in may not necessarily be morally impermissible all things considered. We already accept financial compensation (reimbursement for lost income and travel expenses) for sperm and egg donation. So, our argument goes, if we can save the lives of thousands of people by means of organ donation-linked tax credits the concern for commodification should not outweigh these lives. Here one could argue, as some scholars do, that one can perfectly well favour the reimbursement of funeral expenses to the relatives of organ donors, but oppose tax credits rewarding willingness to donate organs. ${ }^{2}$ The scholars we have in mind here believe that only the former is intended as an expression of society's appreciation of the donation. That is the difference, but the problem with this standpoint is to explain why a tax benefit could not be intended to express society's appreciation of people's willingness to help.

Finally, it is important to distinguish between persons and their bodies. In our view, personal identity is constituted by psychological continuity of the right sort. This continuity may obtain independently of the continuity of all of a person's organs, with the possible exception of the brain. Accordingly, using someone's body (his or her brain excepted) as a commodity need not involve using him or her as a commodity. Therefore, objections to the commodification of persons do not automatically read across to the commodification of transplantable body parts.

\section{Inequality and unequal status}

It might be complained that the benefit of the tax credit system would be unfair as not everybody would have the opportunity to receive the credits. Some people-the obvious case would be the elderly, but there are also people with weak or damaged internal organs-simply do not have organs of the kind transplant surgery requires. However, nothing we have said so far indicates that the basis for tax deduction is not simply agreeing to donate as opposed to agreeing to donate organs that, as a matter of fact, are not substandard. Two reasons speak in favour of the former. First, the administrative burden may be very heavy if every person who signs up is required somehow to demonstrate that his or her organs are of adequate quality for transplantation. Second, most people have at least some organs that can be used even if some cannot. In any case, if there is reason to expect a significant amount of free-riding that would at most motivate adopting a particular version of our proposal, for example, one in which people with substandard organs cannot receive a tax deduction even if they signed up perhaps not knowing their organs were substandard.

Is this unjust? True, the individuals unable to benefit from a tax credit will often be elderly or people (such as patients with cancer, or active alcohol abusers) whose organs are in such a bad state that they are not suitable for donation. These people will probably care more about their own increased chance of survival when the tax credit system is introduced than they would about being denied a small tax benefit. (Admittedly, this increase might not be great as many elderly people and people with serious illnesses are not eligible recipients of organs as they are unlikely to survive transplantation surgery.) So although our proposal might create an inequality specifically in tax credits linked to organ donation, it might well decrease inequalities of longevity. Surely the latter is more important. From an ex ante perspective our scheme would probably reduce overall inequality.

A different, and slightly less tangible, worry is that it would be primarily poor people who sign up as donors, and this would have a symbolic significance that clashes with the idea of citizens relating to one another as equals. ${ }^{30-32}$ This worry itself is 
not an objection to tax incentives as such; it will not apply if there is no significant difference in the willingness of different income groups to donate, and to some extent whether there is might be affected through campaigns targeting particular underdonating groups. Finally, the present objection may apply to schemes not involving any, let alone monetary, advantages of donating if rich donors are drastically underrepresented and poor donors drastically overrepresented.

\section{Better alternatives}

Some might reject our scheme on the grounds that there are better ways to increase the number of organs available for donation. For example, medical staff could be better trained to detect and make use of the organs that are available. Or one could retrieve organs from people who are not brain dead, but who are in an irreversible coma in an intensive care unit with a respirator connected, when the staff and the relatives have decided to allow the person to die because his or her best interests are no longer served by prolonged life; for example, patients in a persistent vegetative state. ${ }^{33}$

It is true that there are other means of increasing the available pool of organs (just as there may be ways of reducing demand for organs, such as by introducing policies designed to curb alcoholism or obesity). What this shows is that the tax credit system whose benefits we are trying to describe should be viewed as a supplement to, not a substitute for, other ways of aligning organ demand and supply.

\section{Expense}

One pragmatic worry is that, for the tax credit scheme to be effective, the credits would need to be offered on such a huge scale that it would simply be too expensive. Imagine two million people in, say, the UK each receiving a tax credit of $£ 200$. Given a $50 \%$ marginal taxation rate, this would equate to a loss of income tax to the state of approximately $£ 200$ million per annum.

This is an awful lot of money, certainly, but it is not clear that it is too much. If, for example, 2 million extra people signed up as organ donors in the UK we could expect the number of people saved by organ donation to be increased. First, the connected increase in the number of organs available for donation might mean that approximately 300 extra lives could be saved annually (assuming that if 18367673 registered people accumulates 3000 donations in a year, then a $10 \%$ increase in the number of people registered should accumulate a $10 \%$ increase in the number of people receiving an organ). ${ }^{34}$ Second, according to the directive of the European parliament and of the Council on Standards of Quality and Safety of Human Organs Intended for Transplantation: 'Organ transplantation is now the most cost-effective treatment for end-stage renal failure and the only available, life saving treatment for end-stage failure of organs such as liver, lung and heart.' According to another study the economic benefits of the average kidney transplant with an anticipated half-life of at least 10 years is well over $£ 300000$. So while our scheme is costly, the scheme should ensure that costs elsewhere in the healthcare system, such as the set-up and running costs of dialysis, are significantly reduced. Finally, the greater availability of organs for transplantation will result in improved quality of life for more donees and their relatives.

Another worry when it comes to financial incentives for organ donation and which is somehow related to expense (but also inequality), is the problem of free-riding. ${ }^{35} 36$ If there are too many people who would receive the tax benefit knowing that they (1) would not be able to donate (eg, because they have a certain condition that renders their organs unsuitable for donation) or (2) because they instruct their families to refuse donation after their death, our proposal could indeed be cost ineffective. Although free-riding cannot be ruled out, the benefits of the proposal might, all things considered, outweigh the social costs of free-riding. The problem with the latter type of free-riding, ie, (2), we deal with in the next section.

\section{Concerns about vetoing by relatives}

Finally, it might be insisted that relatives should be able to veto transplantation of a dead person's organs, and that, in practice, this will be impossible under our scheme if the deceased person has already received and spent the money he was granted as a tax credit.

How serious is this problem? First, we believe any such insistence is misguided; relatives should not have a veto in such cases; it is more important to save lives than it is to allow families a veto over organ disposal. From an impartial point of view, it is morally more important to save the life of someone than to make sure that relatives can, for example, say goodbye to a deceased family member in a specific and organ donation incompatible way. Second, the person whose organs are being donated has consented to donate his or her organs; allowing relatives to veto this decision is incompatible with the right to determine what happens to one's own body. Finally, if these considerations are inconclusive and there is a case for giving relatives a veto, one can modify our proposal to accommodate this-for example, by allowing relatives to veto donation provided that the tax credits are paid back to the state, perhaps from funds in the estate of the deceased. On this proposal both the donor and his or her family will enjoy a veto right over donation.

\section{CONCLUSION}

We have presented five arguments for the view that the value of voluntary organ donation should be recognised in tax credits. We submit: (1) that a strong case can be made for a tax credit scheme of the sort we have described; (2) that this case is robust across a wide range of ethical principles; and (3) that there are no really telling objections to such a scheme. These claims, if correct, point to the conclusion that our proposal should be trialled, at the very least.

\section{Competing interests None.}

Provenance and peer review Not commissioned; externally peer reviewed.

\section{REFERENCES}

1. US Department of Health and Human Services. For a Daily US Update on the Number of Candidates on the Waiting list for an Organ. http://optn.transplant.hrsa. gov/ (accessed 10 Oct 2011).

2. Delmonico FL, Robert A, Scheper-Huges N, et al. Ethical incentives-not payment-for organ donation. N Engl J Med 2002;346:1382-4.

3. NHS Blood and Transplant. Annual Rapport and Accounts 2010-2011. For a daily UK update see NHS Blood and Transplant. http://www.uktransplant.org.uk/ukt/ default.jsp (accessed 10 Oct 2011).

4. Gridelli B, Remuzzi G. Strategies for making more organs available for transplantation. N Engl J Med 2000;343:404-10.

5. Gaston RS, Danovitch GM, Epstein RA, et al. Limiting financial disincentives in live organ donation: a rational solution to the kidney shortage. Am J Transplant 2006;6:2548-9.

6. Matas AJ. Why we should develop a regulated system of kidney sale: a call for action! Clin J Am Soc Nephrol 2006;1:1129-32.

7. McDonalds P. Heart transplantation: who should be considered and when? Intern Med J 2008:38:911-17.

8. Mossialos E, Costa-Font J, Rudisill C. Does organ donation legislation affect individuals' willingness to donate their own or their relative's organs? Evidence from European Union survey data. BMC Health Serv Res 2008;8:48.

9. Johnson EJ, Goldstein D. Do defaults save lives? Science 2003;302:1338-9. 
10. Lavee J, Ashkenazi T, Gurman G, et al. A new law for allocation of donor organs in Israel. Lancet 2010;375:1131-3.

11. Lavee J, Ashkenazi T, Gurman G, et al. A new law for allocation of donor organs in Israel-Authors' reply. Lancet 2010;376:231-2.

12. Taylor JS. Stakes and Kidneys: Why Markets in Human Body Parts are Morally Imperative. Farnham: Ashgate, 2005

13. Blumstein JF. In: Singer P, Kuhse H, eds. Legalising Payment for Transplantable Cadaveric Organs. Bioethics: An Anthology. Oxford: Blackwell, 1999.

14. Cversky A, Kahneman D. The framing of decisions and the psychology of choice. Science 1981;211:453-8.

15. Savulescu J. Death, us and our bodies: personal reflections. J Med Ethics 2003;29:129.

16. Parker FR, Winslade WJ, Paine CJ. Organ procurement and tax policy. Houst $J$ Health Law Policy 2002;2:173-85.

17. Illingworth P. Giving back. In: Illingworth P, Pogge T, Wenar L, eds. Giving Well: The Ethics of Philanthropy. Oxford University Press, 2011:196-219.

18. The Gallup Organization, I. The American Public's Attitude Toward Organ Donation and Transplantation. Boston, MA: The Partnership for Organ Donation, 1993.

19. Danish Health Department. Attitudes on Organ Donation (in Danish). Copenhagen: Danish Health Department, 2007.

20. Arneson R. Equality and equal opportunity for welfare. Philos Stud 1989;56:77-93

21. Nozick R. Anarchy, State, and Utopia. New York: Basic Books, 1974.

22. Cohen GA. Self-Ownership, Freedom and Equality, chapter 10. Cambridge: Cambridge University Press, 1995.

23. Fabre C. Whose Body Is It Anyway? Oxford: Oxford University Press, 2006:31.
24. Kittur DS, Hogan MM, Thukral VK, et al. Incentives for organ donation? Lancet 1991:2:1441

25. Titmuss RM. Why give to strangers? In: Kuhse $\mathrm{H}$, Singer P, eds. Bioethics: An Anthology. 1999:386-92.

26. Wertheimer A. Exploitation. Stanford Encyclopedia of Philosophy. http://plato stanford.edu/entries/exploitation/ (accessed 24 Oct 2011).

27. Honderich T. Exploitation. Oxford: The Oxford Companion to Philosophy, 1995

28. Radin JM. Contested Commodities. Harvard: Harvard University Press, 2001.

29. Kant I. Grundlegung zur Metaphisik der Sitten. Reprint of 1870 edition edited by Heimann L. Boston: Adament Media Corporation, 2000.

30. Anderson E. What is the point of equality? Ethics 1999;109:287-337.

31. Satz D. Why Some Things Should Not Be For Sale: The Moral Limits of Markets. Oxford: Oxford University Press, 2010.

32. Scheffler S. What is Egalitarianism? Philos Public Aff 2003:31:5-39.

33. Wilkinson D, Savulescu J. Should we allow organ donation euthanasia? Bioethics 2011. Published Online First: doi:10.1111/j.1467-8519.2010.01811.x laccessed 3 May 2010).

34. NHS Blood and Transplant - Organ Donation. http://www.uktransplant.org.uk/ ukt/default.jsp (accessed 24 Oct 2011).

35. Quigley M. Incentivising organ donation. In: Farell AM, Price D, Quigley M, eds Organ Shortage: Ethics, Law and Pragmatism. Cambridge: Cambridge University Press, 2007:89-103.

36. Dijk $G$ v Hilhorst MT. Financial Incentives for Organ Donation: An Investigation of the Ethical Issues. Ethics and Health Monitoring Report 2007/3. The Hague: Centre for Ethics and Health, 2007. 